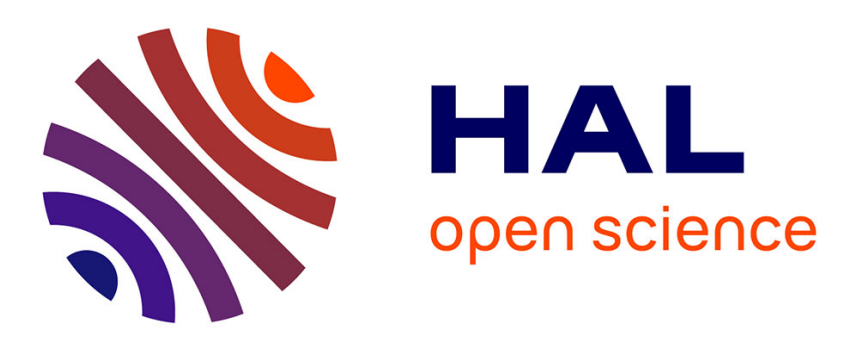

\title{
Enhanced Sensing Characteristics in MEMS-based Formaldehyde Gas Sensor
}

Yu-Hsiang Wang, C.-C. Hsiao, Chia-Yen Lee, R.-H. Ma, Po-Cheng Chou

\section{To cite this version:}

Yu-Hsiang Wang, C.-C. Hsiao, Chia-Yen Lee, R.-H. Ma, Po-Cheng Chou. Enhanced Sensing Characteristics in MEMS-based Formaldehyde Gas Sensor. DTIP 2007, Apr 2007, Stresa, lago Maggiore, Italy. pp.264-268. hal-00257700

\section{HAL Id: hal-00257700 \\ https://hal.science/hal-00257700}

Submitted on 20 Feb 2008

HAL is a multi-disciplinary open access archive for the deposit and dissemination of scientific research documents, whether they are published or not. The documents may come from teaching and research institutions in France or abroad, or from public or private research centers.
L'archive ouverte pluridisciplinaire HAL, est destinée au dépôt et à la diffusion de documents scientifiques de niveau recherche, publiés ou non, émanant des établissements d'enseignement et de recherche français ou étrangers, des laboratoires publics ou privés. 


\title{
ENHANCED SENSING CHARACTERISTICS IN MEMS-BASED FORMALDEHYDE GAS SENSOR
}

\author{
Yu-Hsiang Wang ${ }^{1}$, Ching-Cheng Hsiao ${ }^{1}$, Chia-Yen Lee ${ }^{1}$, Rong-Hua $\mathrm{Ma}^{2}$, Po-Cheng Chou ${ }^{3}$ \\ ${ }^{1}$ Department of Mechanical and Automation Engineering, Da-Yeh University, Changhua, Taiwan, \\ ${ }^{2}$ Department of Mechanical Engineering, Chinese Military Academy, Kaohsiung, Taiwan, \\ ${ }^{3}$ Department of Interior Design, Shu-Te University of Science and Technology, Kaohsiung, Taiwan.
}

\begin{abstract}
In this study, the proposed sensor integrates a sensing layer, a heating device, and electrodes on the substrate. The micro heater is integrated in the sensor to provide instantaneous and precise temperature control capability. The electrodes are fabricated to connect resistance meter for measuring variation of electrical conductibility of the sensing layer. The grain size of the $\mathrm{NiO}$ thin film is almost to be nanometer level, and therefore both the sensitivity and the lowest sensing limit of the device are enhanced due to the enlarged area of the catalyst grains contacting with the surrounding gas. The experimental data show that decreasing thickness of sensing layer in the sputtering process significantly increases the sensitivities of the gas sensor and improves its lowest detection limit capability (0.7 ppm). Although we can further improve lowest detection limit by co-sputtering with $\mathrm{NiO} / \mathrm{Al}_{2} \mathrm{O}_{3}(40 \mathrm{ppb})$, it needs to consider that selectivity will be reduced. The integrated micro heater simplifies the experimental set-up and can be realized using a simple fabrication process. The presented microfabricated formaldehyde gas sensor with a self-heating $\mathrm{NiO} / \mathrm{Al}_{2} \mathrm{O}_{3}$ thin film is suitable not only for industrial process monitoring but for safeguarding the human health in buildings.
\end{abstract}

\section{INTRODUCTION}

Formaldehyde is an important chemical that used widely by industry to manufacture building materials and numerous household products. But it can cause irritation of the skin, eyes, nose, and throat. High levels of exposure may cause some types of cancers. It has been shown that throat and nose irritation can occur at formaldehyde levels as low as $0.08 \mathrm{ppm}$ [1]. The WHO (World Health Organization) has established a permissible long-term exposure limit of $0.1 \mathrm{ppm}$ [2]. The methods of detection for formaldehyde gas may divide into three main categories: GC/MS, optical, and MEMS based gas sensor. The principle of GC/MS is achieved using a stringent semi-batch air-sampling procedure, followed by a batch analysis of the sample, but it is benchtop and sampled by a tube with absorbent. Thus numerous researchers have studied about optical sensor for formaldehyde quantification applications [3-4]. Even though the optical sensors are simultaneous sampling and have instantaneous analyzing time, associated optical arrangements tend to be rather bulky and elaborate. In the last decade, emerging MEMS and micromachining techniques have led to the development of miniaturized sensing instrumentation capable of accessing information at a microscale level. Importantly, the functionality and reliability of these micro sensors can be increased through their integration with mature logic IC technology or with other sensors.

Recently, Dirksen et al. [2] proposed a NiO thin-film formaldehyde gas sensors by dipping alumina substrates in a nickel acetylacetoneate solution to form thin $\mathrm{NiO}$ films of thickness $0.5 \mu \mathrm{m}$. It was found that the conductivity of these films changed as the formaldehyde concentration was varied at temperatures ranging from 400-600 ${ }^{\circ} \mathrm{C}$. At approximately $3 \mu \mathrm{m}$, the sintered grain size was rather large and was hence expected to reduce the sensitivity of the device. However, a linear formaldehyde sensitivity of $0.825 \mathrm{mV} \mathrm{ppm}^{-1}$ was attained at a temperature of $600{ }^{\circ} \mathrm{C}$. Although the sensor demonstrated a high sensitivity, its detection limit was only $50 \mathrm{ppm}$, i.e. far higher than the prescribed "maximum permissible long-term exposure" limit of 0.1 ppm. Furthermore, the proposed sensor lacked an integrated heating device capable of maintaining the optimal working temperature of $600{ }^{\circ} \mathrm{C}$. Therefore, the sensor operation required the use of an external heater, which not only increased the bulk of the sensor arrangement, but also increased its power consumption. As a means of overcoming this problem, Lee et al. [5] proposed the use of $\mathrm{Pt}$ resistors as integrated microheaters for MEMS-based temperature control systems. Pt was chosen specifically as the resistor material on account of its physical and chemical stability. The current study develops a new process for the fabrication of a MEMSbased formaldehyde sensing device comprising micro heater and electrodes with $\mathrm{Pt}$ resistance heaters and a 
sputtered $\mathrm{NiO} / \mathrm{Al}_{2} \mathrm{O}_{3}$ layer. The experiment data indicate a high sensitivity, a low detection limit, a simple arrangement with no requirement for any from of external heating device.

\section{EXPERIMENTAL}

\subsection{Design}

In this study, the proposed sensor integrates a sensing layer, a heating device, and electrodes on the substrate. The micro heater is integrated in the sensor to provide instantaneous and precise temperature control capability. The electrodes are fabricated to connect resistance meter for measuring variation of electrical conductibility of the sensing layer. The grain size of the $\mathrm{NiO}$ thin film is almost to be nanometer level, and therefore both the sensitivity and the lowest sensing limit of the device are enhanced due to the enlarged area of the catalyst grains contacting with the surrounding gas. As shown in figure 1, we design two types of sensors for different micro heater positions and sensing layers. Type $A$ is the micro heater above the sensing layer, and the other one (type B) is fabricated the micro heater between the sensing layer and the substrate. Table 1 shows the detail of design in this study, we not only tried to compare the characteristic of sensor with type $\mathrm{A}$ and type $\mathrm{B}$ but also attempted decrease the thickness of sensing layer and deposited the sensing layer by "co-sputtering" with $\mathrm{NiO} / \mathrm{Al}_{2} \mathrm{O}_{3}$ to improve the sensitivity and the lowest sensing limit of the sensor.

\subsection{Microfabrication}

The gas sensors of this study were fabricated by using quartz substrates as the substrate. Figure 2 presents a schematic illustration of the fabrication process of type A and type B. As shown in figure 2(a) (type A) a $\mathrm{NiO}$ sensing layer was prepared using an RF magnetron sputtering system with a $\mathrm{NiO}$ target of $99.98 \%$ purity [8]. The oxide was sputtered on substrates, which were placed at a distance of $11.4 \mathrm{~cm}$ from the $\mathrm{NiO}$ target. Sputtering was performed under a gas pressure of 0.01 torr with the target maintained at a constant RF power of $200 \mathrm{~W}$. The reactive sputter gas was a mixture of argon $(50 \%)$ and pure oxygen gas $(50 \%)$. The substrate temperature during sputtering was $400{ }^{\circ} \mathrm{C}$ [9]. Prior to deposition, the chamber was pumped to a background pressure of 10-6 torr for $1 \mathrm{~h}$ and a pre-sputtering process was performed
Table 1: Design of formaldehyde sensors with different micro heater position and parameters.

\begin{tabular}{|c|c|c|}
$\begin{array}{c}\text { Micro heater } \\
\text { position } \\
\begin{array}{l}\text { Sensing layer } \\
\text { thickness }\end{array}\end{array}$ & $\begin{array}{c}\text { Above } \\
\text { sensing layer }\end{array}$ & $\begin{array}{c}\text { Below } \\
\text { sensing layer }\end{array}$ \\
\hline $1500 \AA$ & $\mathrm{A}_{1500}$ & $\mathrm{~B}_{1500}$ \\
\hline $500 \AA$ & & $\mathrm{B}_{500-\mathrm{NiO}}$ \\
\hline $\begin{array}{c}500 \AA \\
(\text { co-sputtering) }\end{array}$ & & $\mathrm{B}_{500-\mathrm{NiO} / \mathrm{Al} 2 \mathrm{O} 3}$ \\
\hline
\end{tabular}

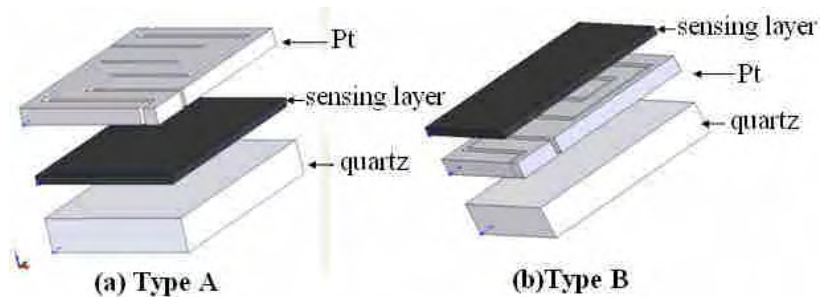

Fig. 1: Schematic illustration of formaldehyde sensors with different micro heater position.

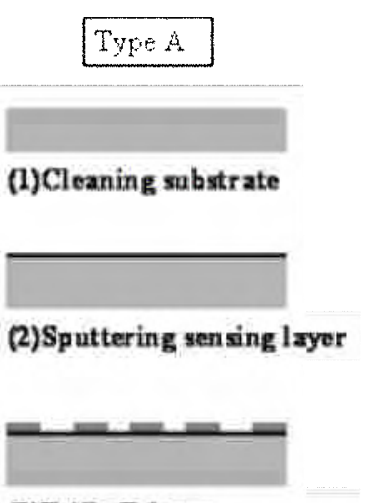

(3)PuCr B-beam

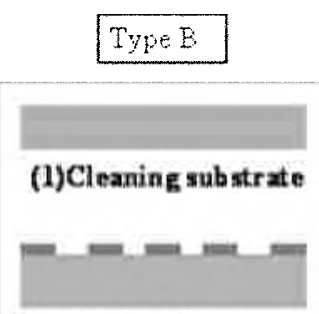

(2) PtCr E-beam
Fig. 2: schematic illustration of the simplified fabrication process of type A and type B

for $10 \mathrm{~min}$ to clean the target surface by removing any possible traces of contamination. To control the thin film thickness, the deposition time was 10 hours. The deposited $\mathrm{NiO}$ films was found to have thickness of approximately $1500 \AA$. A thin layer of $\mathrm{Cr}(0.02 \mu \mathrm{m})$ was then deposited as an adhesion layer for the subsequent electro-beam evaporation of a Pt layer of $0.2 \mu \mathrm{m}$ thickness. A standard lift-off process was employed to pattern the $\mathrm{Pt} / \mathrm{Cr}$ layer to form a micro heater and the electrodes on the NiO sensing layer. The resistance of the heater was designed to be $30 \Omega$. As shown as figure 2(b) (type B), electron-beam evaporation and lift-off procedures were 
then repeated to deposit and shape Pt micro heater and electrodes. Then $\mathrm{NiO}$ sensing layer was sputteringdeposited.

\section{RESULTS AND DISCUSSION}

\subsection{Effect of substrate temperature and micro heater position with sensing layer}

As shown in figure 3, a linear dependency is observed between the resistance and the formaldehyde concentration at different sensor working temperatures (i.e. micro-heater temperatures). The slopes of the plotted lines represent the sensitivity of the device and are found to be $-0.137 \Omega \mathrm{ppm}^{-1}$ at $280{ }^{\circ} \mathrm{C},-0.12 \Omega \mathrm{ppm}^{-1}$ at $215^{\circ} \mathrm{C}$, and $-0.104 \Omega \mathrm{ppm}^{-1}$ at $150{ }^{\circ} \mathrm{C}$, respectively. The lowest detection limit of the type $\mathrm{A}_{1500}$ sensor is determined to be $1.2 \mathrm{ppm}$ at $280{ }^{\circ} \mathrm{C}$. As shown in figure 4, a linear dependency is also observed between the resistance and the formaldehyde concentration at different sensor working temperatures. The sensitivities of the type $B_{1500}$ are found to be $-0.335 \Omega \mathrm{ppm}^{-1}$ at $300{ }^{\circ} \mathrm{C},-0.293 \Omega \mathrm{ppm}^{-}$ ${ }^{1}$ at $250{ }^{\circ} \mathrm{C}$, and $-0.181 \Omega \mathrm{ppm}^{-1}$ at $180{ }^{\circ} \mathrm{C}$, respectively. The lowest detection limit of the type $\mathrm{B}_{1500}$ sensor is determined to be $0.8 \mathrm{ppm}$ at $280{ }^{\circ} \mathrm{C}$ By the results between type $A_{1500}$ and $B_{1500}$, it is clear to find:

1. When the working temperatures of the substrate increases, the sensitivity of the sensor increases.

2. Because the area of the sensing layer contacting with the surrounding gas on sensor type B is larger than that of type A, the sensitivity level increases and the lowest detection limit is also improved from $1.20 \mathrm{ppm}$ to $0.8 \mathrm{ppm}$.

\subsection{Effect of sensing layer thickness and materials}

For approaching higher sensitivity and better characteristics of the sensors, we fabricated the sensing layer thickness approximately $500 \AA$ by type B fabrication, and deposited the sensing layer by "co-sputtering" with $\mathrm{NiO} / \mathrm{Al}_{2} \mathrm{O}_{3}$ to compare the results at different sensing layer thickness and materials of sensing layer. Figure 5 and 6 show X-ray diffraction analysis (XRD) for sensing layer of type $\mathrm{B}_{500-\mathrm{NiO}}$ and type $\mathrm{B}_{500-\mathrm{NiO} / \mathrm{Al2O}}$, respectively. In figure 5 and 6 , we can clearly find the peak of $\mathrm{NiO}$ and Pt. However, we cannot find any peak of $\mathrm{Al}_{2} \mathrm{O}_{3}$ in figure 6 , even though we deposited the sensing layer of $\mathrm{B}_{500}$ $\mathrm{NiO} / \mathrm{Al}_{2} \mathrm{O}_{3}$ by co-sputtering technology with $\mathrm{NiO} / \mathrm{Al}_{2} \mathrm{O}_{3}$. The $\mathrm{Al}_{2} \mathrm{O}_{3}$ of the sensing layer of $\mathrm{B}_{500-\mathrm{NiO} / \mathrm{Al} 2 \mathrm{O} 3}$ is amorphous alumina [7]. In figure 7 and 8 , the lowest detection limit of type $\mathrm{B}_{500-\mathrm{NiO}}$ and $\mathrm{B}_{500-\mathrm{NiO} / \mathrm{Al} 2 \mathrm{O} 3}$ were determined, respectively. We can find the sensing layer of $\mathrm{NiO} / \mathrm{Al}_{2} \mathrm{O}_{3}$ improve the lowest detection limit from $0.7 \mathrm{ppm}$ to $40 \mathrm{ppb}$. Although it can improve the lowest

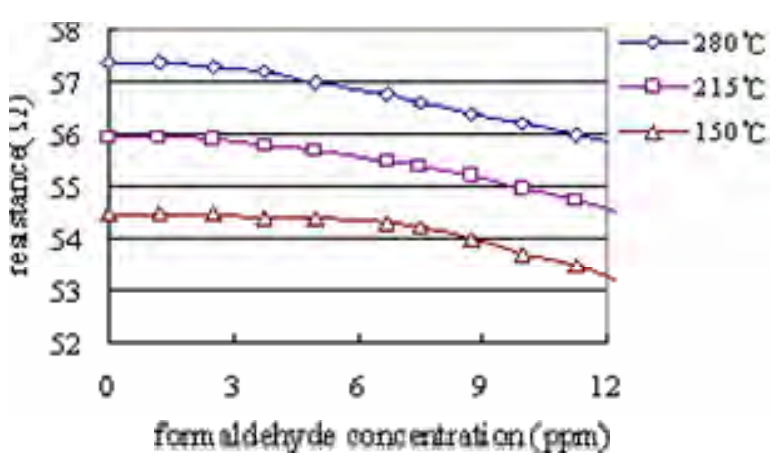

Fig. 3: Experimental results of type $A_{1500}$ sensor at different work temperature.

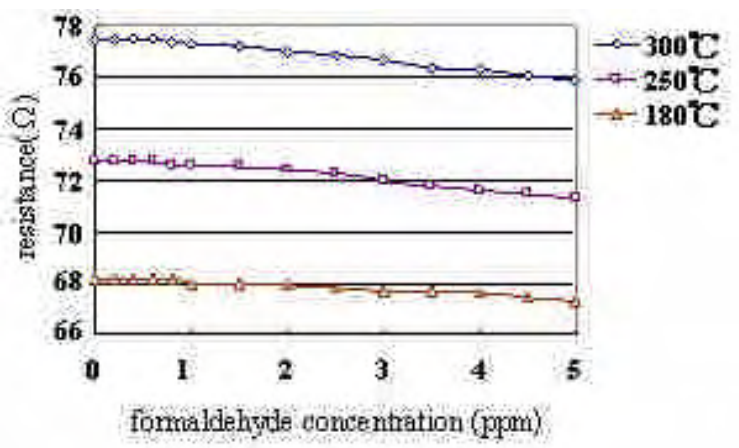

Fig. 4: Experimental results of type $B_{1500}$ sensor at different work temperature.

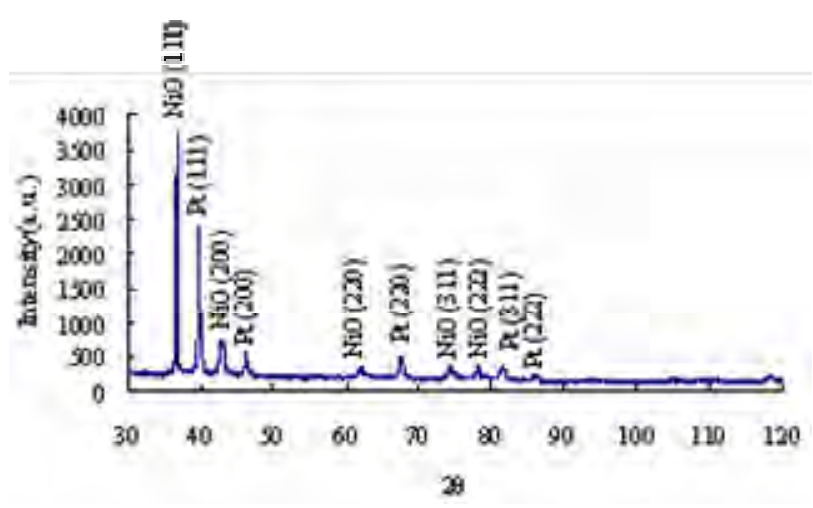

Fig. 5: XRD diffraction patterns of $\mathrm{NiO}$ thin film.

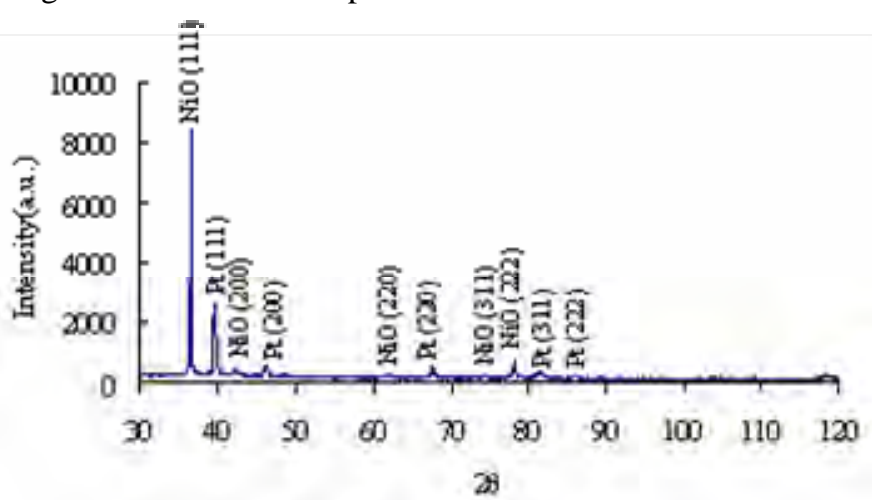

Fig. 6: XRD diffraction patterns of $\mathrm{NiO} / \mathrm{Al} 2 \mathrm{O} 3$ thin film. 


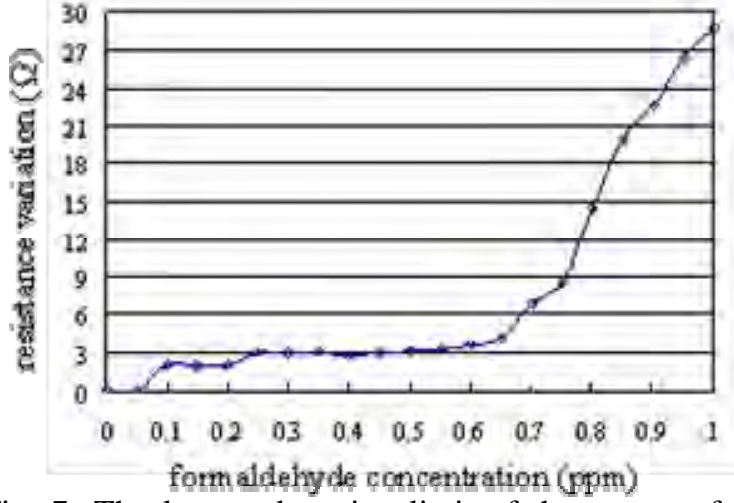

Fig. 7: The lowest detection limit of the sensor of type $\mathrm{B}_{500-\mathrm{NiO}}$

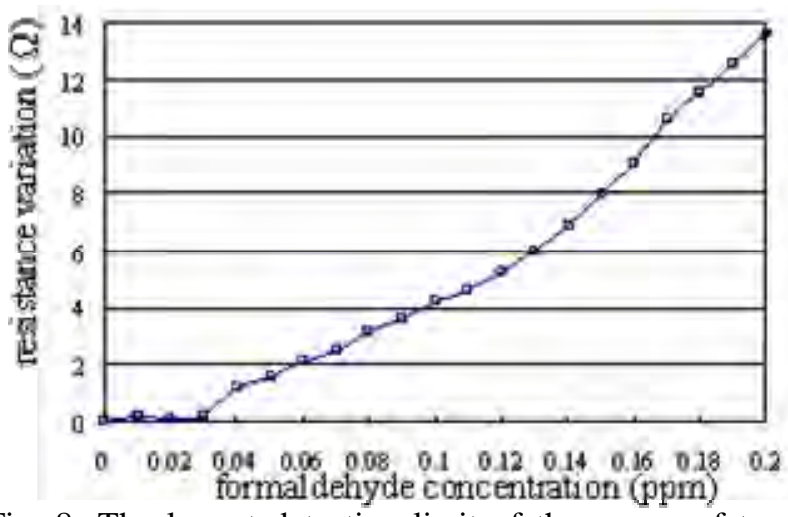

Fig. 8: The lowest detection limit of the sensor of type $\mathrm{B}_{500-\mathrm{NiO} / \mathrm{Al} 2 \mathrm{O} 3}$

detection limit by co-sputtering with $\mathrm{NiO} / \mathrm{Al}_{2} \mathrm{O}_{3}$, but the selectivity of the sensor will also be reduced, as shown in figure 9 and 10. In figure 9, a high selectivity over a wide formaldehyde concentration range in the presence of interfering species such as acetone, ethanol and methanol. However, figure 10 indicates the selectivity of type $\mathrm{B}_{500}$ $\mathrm{NiO} / \mathrm{Al} 2 \mathrm{O} 3$ was reduced by sensing layer of $\mathrm{NiO} / \mathrm{Al}_{2} \mathrm{O}_{3}$.

\subsection{Time response}

In conventional gas detectors, the time required for formaldehyde concentration measurement can vary from hours to days. However, a requirement exists for sensors with a real-time gas detection and measurement capability. Figure 11 and 12 presents the time response of the gas sensors developed in the present study. The average time constant of the proposed formaldehyde gas sensor is determined to be $7 \mathrm{~s}$ and $6 \mathrm{~s}$ for type $\mathrm{B}_{500-\mathrm{NiO}}$ and $\mathrm{B}_{500-}$ $\mathrm{NiO} / \mathrm{Al} 2 \mathrm{O} 3$ sensor at a micro-heater temperature of $300{ }^{\circ} \mathrm{C}$.

\section{CONCLUSIONS}

This study has successfully demonstrated a novel selfheating formaldehyde gas sensor based on a thin film of

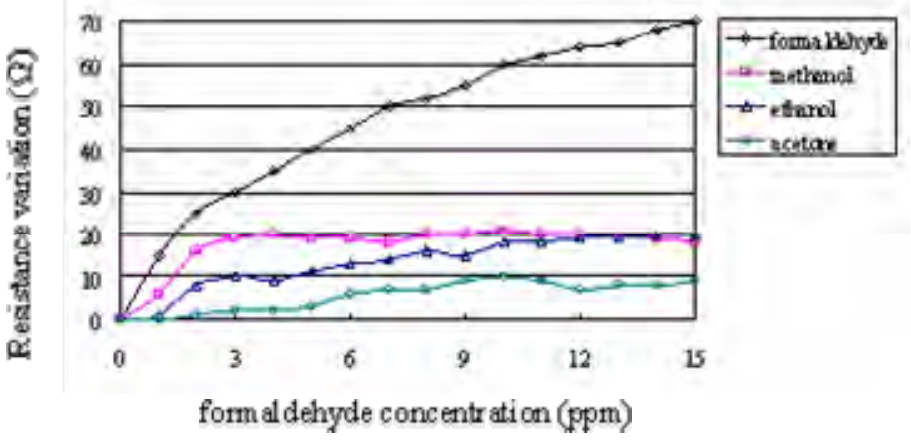

Fig. 9: The selectivity of the sensor type $\mathrm{B}_{500-\mathrm{NiO}}$.
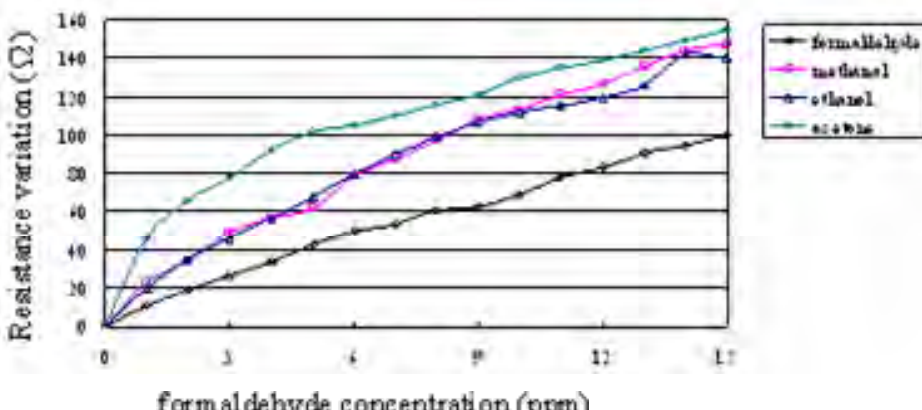

Fig. 10: The selectivity of the sensor type $\mathrm{B}_{500-\mathrm{NiO} / \mathrm{Al} 2 \mathrm{O} 3}$.

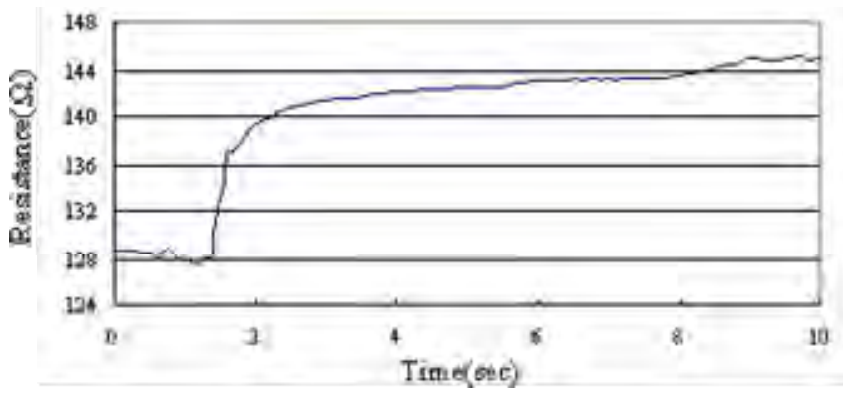

Fig. 11: Response transient of the formaldehyde gas sensor for type $\mathrm{B}_{500-\mathrm{NiO}}$

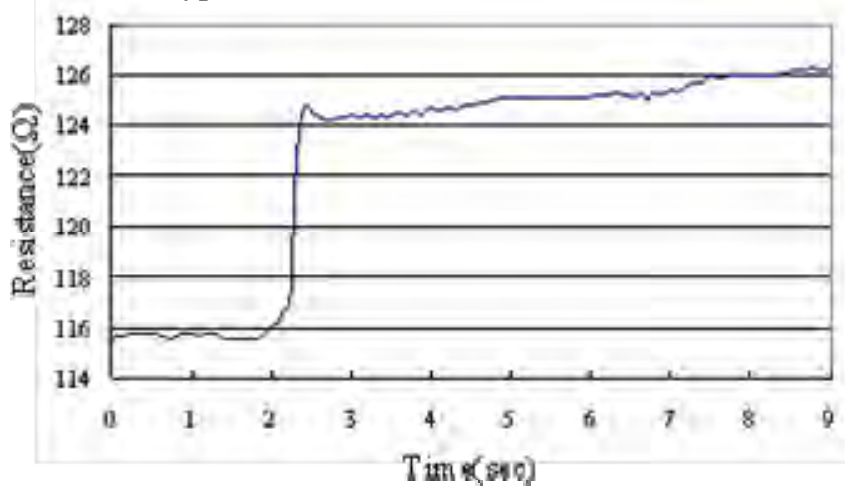

Fig. 12: Response transient of the formaldehyde gas sensor for type $\mathrm{B}_{500-\mathrm{NiO} / \mathrm{Al} 2 \mathrm{O} 3}$ 
$\mathrm{NiO}$ sensing layer. A new fabrication process has been developed in which the $\mathrm{Pt}$ micro-heater and electrodes are deposited directly on the substrate and the $\mathrm{NiO}$ thin film is deposited above on the micro heater to serve as sensing layer. Pt electrodes are formed below the sensing layer to measure the electrical conductivity changes caused by formaldehyde oxidation at the oxide surface. The experimental data show that decreasing thickness of sensing layer in the sputtering process significantly increases the sensitivities of the gas sensor and improves its lowest detection limit capability $(0.7 \mathrm{ppm})$. Although we can further improve lowest detection limit by cosputtering with $\mathrm{NiO} / \mathrm{Al}_{2} \mathrm{O}_{3}$ (40 ppb), it needs to consider that selectivity will be reduced. The integrated micro heater simplifies the experimental set-up and can be realized using a simple fabrication process. The presented microfabricated formaldehyde gas sensor with a selfheating $\mathrm{NiO} / \mathrm{Al}_{2} \mathrm{O}_{3}$ thin film is suitable not only for industrial process monitoring but for safeguarding the human health in buildings.

\section{ACKNOWLEDGEMENTS}

The authors would like to thank the financial support provided by the National Science Council in Taiwan (NSC 95-2211-E-212-058 and NSC 95-2218-E-006-022).

\section{REFERENCES}

[1] Air Quality Guidelines, 2nd Ed, chap. 5.8, WHO Regional Office for Europe, Copenhagen, Denmark, 2001. [2] J.A. Dirksen, K. Duval, T.A. Ring, "NiO thin-film formaldehyde gas sensor", Sens. Actuators, B, Chem, vol. 80, pp. 106-115, 2001.

[3] Y. Mine, N. Melander, D. Richter, D.G. Lancaster, K.P. Petrov, R.F. Curl, F.K. Tittel, "Detection of formaldehyde using mid-infrared difference-frequency generation”, Applied Physics B, vol. 65, pp. 771, 1997.

[4] S. Friedfeld, M. Fraser, "Field intercomparison of a novel optical sensor for formaldehyde quantification", Geophysical Research Letters, vol. 27 (14), pp. 2093, 2000.

[5] C.Y. Lee, G.B. Lee, H.H. Liu, F.C. Huang, "MEMSbased temperature control systems for PCR applications", The International Journal of Non-linear Sciences and Numerical Simulations, vol. 3, pp.177 , 2002.

[6] M. Matsumiya, F. Qiu, W. Shin, N. Izu, N. Murayama, S. Kanzaki, "Thin-film Li-doped $\mathrm{NiO}$ for thermoelectric hydrogen gas sensor", Thin Solid Films, vol. 419, pp. 213217, 2002.

[7] K.F. Chiu, C.C. Dai, "Bias sputter deposited $\mathrm{Ni} / \mathrm{Al} 2 \mathrm{O} 3$ cermet thin films for gas flow sensors", Thin Solid Films, vol. 513, pp. 374-379, 2006.
[8] S.R. Jiang, P.X. Yan, B.X. Feng, X.M. Cai, J. Wang, "The response of a NiOx thin film to a step potential and its electrochromic mechanism", Mater. Chem. Phys., vol. 77, pp. 384-389, 2002.

[9] Y.M. Lu, W.S. Hwang, J.S. Yang, "Effects of substrate temperature on the resistivity of nonstoichiometric sputtered NiOx films", Surf. Coat. Technol, vol. 155 , pp. 231-235, 2002. 